\title{
Predictive Control System of Gas Recovery Based on Neural Network and Fuzzy Control
}

\author{
H.Y. Bian \\ College of Physics \& Electric-Information Engineering \\ Pingdingshan University \\ China
}

\begin{abstract}
Aiming at the problem that the converter gas steam recovery and average recovery rate is less than forty percent in some steel factory, this research optimized recycle-using system of steel plant's converter gas by applying neural-network adaptive predictive control and fuzzy control. The simulation results showed that furnace gas emissions could reach $-5 \sim 5 \mathrm{~L} / \mathrm{h}$, and the practice proved the average recovery of gas reached $97.5 \mathrm{~m} 3 / \mathrm{T}$ after applying neural-network adaptive predictive control in practical application.
\end{abstract}

Keywords-predictive control system; gas recovery; neural-network; fuzzy control

\section{INTRODUCTION}

90-120 $\mathrm{m}^{3}$ gas can be recovered when per ton steel is made in the steel plant, the heating value of that gas reach about $1800 \sim 2000 \mathrm{kcal} / \mathrm{m}^{3}$, which is more than twice as high as the blast furnace gas heating and is secondary energy only less than the coke oven gas[1,2]. Take into account environmental protection and energy saving, the domestic large scale steel plants build almost gas recovery control system, but the recovery effect is not ideal[3]. Therefore, it is necessary for the steel plants to establish gas recovery control system.

Gas recovery systems of the steel mills have large delay, nonlinear and uncertainty features[4], it is very difficult to describe accurately the thermal process and implement the overall optimization by applying the traditional dynamic mathematical model control method[5,6], therefore, it is very necessary apply the advanced control method to the gas recovery system.

Aiming at the problem that the converter gas steam recovery and average recovery rate is less than forty percent in a certain steel factory, this research optimized recycle-using system of steel plant's converter gas by applying neural-network adaptive predictive control and fuzzy control.

\section{GAS RECOVERY SYSTEM AND CONTROL STRATEGIES SITUATION IN A CERTAIN STEEL PLANT}

\section{A. The Principle of Gas Recovery System}

The principle diagram of gas recovery system in a steel plant is shown in figure 1 . Where 1 is the open hearth furnace, 2 is micro different pressure of the open hearth furnace, 3 is pre-washing tower, 4 is overflow entrance flow amount, 5 is RS entrance gas temperature, 6 is RS entrance pressure, 7 is

\author{
Y.L. Chang \\ Mechanical \& Electrical Engineering Department \\ College of Henan Quality Project \\ China
}

entrance flow of pre-washing tower, 8 is tension weight displacement, 9 is tension weight, 10 is controller signals, 11 is controller, 12 is uplink signals, 13 is downlink signals, 14 is proportional valve, 15 is cylinder, 16 is the outlet pressure of RS, 17 is dewatering device.

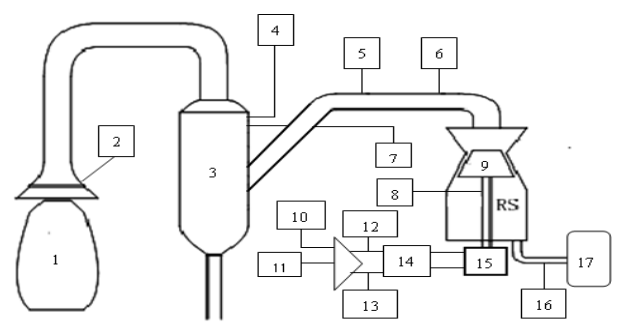

FIGURE 1. THE PRINCIPLE DIAGRAM OF GAS RECOVERY SYSTEM.

The principle of gas recovery can be understood from figure 1. Blast furnace gas passes pre-washing tower and RS after it is overflowed from the open hearth furnace mouth, which can be recovered and utilized after passing the dehydrator. The washing tower is mainly to remove the dust of the coal gas; RS controls mainly the flow of the coal gas. The throat mouth of RS becomes small, the wind resistance is increased and the gas flow becomes smaller when the tension weight goes up; On the contrary, gas flow becomes large. The tension weight needs to go down in order to expand the opening amount of the throat mouth, increase the gas flow and prevent the coal gas of the open hearth furnace mouth overflowing to the factory when the amount of overflow from the coal gas of the open hearth furnace mouth is larger. The tension weight needs to go up in order to reduce the opening amount of the throat mouth, reduce the gas flow and prevent the excessive air and low concentration in the recovery gas when the amount of overflow from the coal gas of the open hearth furnace mouth is smaller.

\section{B. Control Strategies of The Gas Recovery System At Present}

The major control strategies of the gas recovery system in a steel plant at present are as follows[4-7]:

(1) The tension weight is not action within two and a half minutes after the gas recovery system is opened;

(2) A control period of the tension weight is three seconds, two seconds are running and a second is stop state;

(3) The controller applies programmable logical controller; 
(4) Micro differential pressure signal of the open hearth furnace mouth is the control signals of the tension weight, this is input signal of the controller;

(5) Control method uses proportion control.

The major problems of the gas recovery control strategies in a steel plant are as follows:

(1) Average recovery rate of the gas recovery is less than forty percent;

(2) The gas mount of overflowing to the plant is more, which leads to serious air pollution in workshop;

(3) The air content of the recovered gas is much larger.

\section{CONTROL STRATEGIES OF THE GAS RECOVERY SYSTEM BASED} ON NEURAL NETWORK

\section{A. Control Principles of The Gas Recovery System Based on Neural Network and Fuzzy Control}

There are about 40 meters pipeline and pre-washing tower from the micro differential pressure gauge of the open hearth furnace mouth to RS, as is shown in figure 1. Gas recovery system has pure delay characteristics because of the compressible features of gas[8]; system response is slower for the pure delay system. Therefore, the advanced control technology must be applied to this kind system in order to improve the control precision of the system. Figure 2 is the control model schematic diagram of gas recovery system.

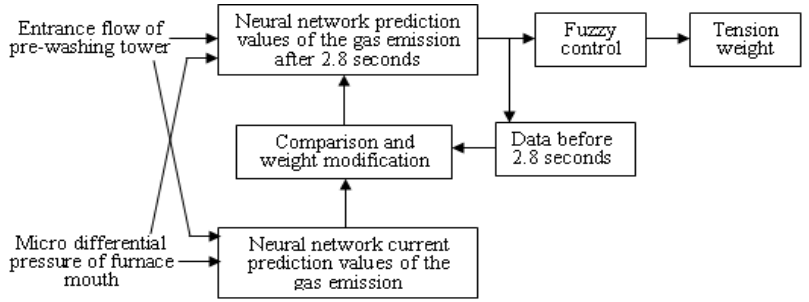

FIGURE 2. THE CONTROL MODEL SCHEMATIC DIAGRAM OF GAS RECOVERY SYSTEM.

Control principles in figure 2 are as follows: Input variables of the control system are entrance flow of pre-washing tower and micro differential pressure of the open hearth furnace mouth. Neural network is applied to estimate the gas emission current value and predict the gas emission value after 2.8 seconds at the open hearth furnace mouth, the two values are compared and then modify the weight of neural network; 2.8 seconds are a result of system identification by neural network. Gas emission amount is a key input variable of neural network and fuzzy control module. Tension weight is system actuator.

\section{B. Adaptive Prediction Based on Neural Network}

Neural network is applied to predict gas emission value of the open hearth furnace mouth because neural network has very good ability of nonlinear mapping[9]. Gas flow difference is ignored between the open hearth furnace mouth and pre-washing tower, the first ten measurement values of pre-washing tower entrance flow and micro differential pressure at the open hearth furnace mouth are as input values of neural network. Because the system delay is about 2.8 seconds, so the prediction results are the gas emission amount of the open hearth furnace mouth after 2.8 seconds. Figure 3 is neural network model.

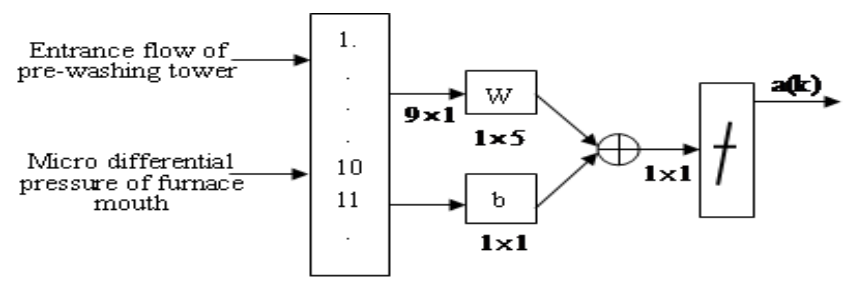

FIGURE 3. NEURAL NETWORK MODEL.

Decreasing gradient algorithm is adopted to adjust the weight value of neural network according to the measured data and the neural network model established, which makes the output values of neural network approach gas emission value $\mathrm{a}(\mathrm{k})$ of the open hearth furnace mouth after 2.8 seconds.

\section{Fuzzy Control Algorithm}

It is very difficult to establish the precise mathematical model because gas recovery systems of steel plants have nonlinear and uncertainty. However, fuzzy control method does not need to build the mathematics model of the controlled object because it need only to set up a certain object mapping relationship according to the expert knowledge and experience[10]. Therefore, it is a better control method that fuzzy control and neural network are combined to achieve control of gas recovery system.

Fuzzy control linguistic variable of gas emission amount are as follows: the range of error e is $\{-20 \mathrm{~Pa} 、+10 \mathrm{~Pa}\}$; The range of error changing rate $\mathrm{Ec}$ is $\{-20 \mathrm{~Pa} / \mathrm{s}, 20 \mathrm{~Pa} / \mathrm{s}\}$; The range of output $U$ is $\{4 \mathrm{~mA}, 25 \mathrm{~mA}\}$. Fuzzy state of each linguistic variable is $\{\mathrm{NB}, \mathrm{NM}, \mathrm{NS}, \mathrm{ZO}, \mathrm{PS}, \mathrm{PM}, \mathrm{PB}\}$. Control rules of the parameter $\mathrm{U}$ can be determined according to the parameter $\mathrm{e}$ and Ec. Control rules of parameter $\mathrm{U}$ is shown in Table 1.

TABLE I. CONTROL RULES OF U.

\begin{tabular}{|c|c|c|c|c|c|c|c|}
\hline \multirow{2}{*}{$\mathrm{e}$} & \multicolumn{7}{|c|}{ ec } \\
\cline { 2 - 8 } & NB & NM & NS & ZO & PS & PM & PB \\
\hline NB & PB & PB & PM & PM & PS & ZO & ZO \\
\hline NM & PB & PM & PM & PS & PS & ZO & ZO \\
\hline NS & PM & PM & PS & PS & ZO & NS & NM \\
\hline ZO & PM & PS & PS & ZO & NS & NM & NM \\
\hline PS & PS & PS & ZO & NS & NM & NM & PB \\
\hline PM & ZO & ZO & NS & NM & NM & PB & PB \\
\hline PB & ZO & ZO & NM & NM & PB & PB & PB \\
\hline
\end{tabular}

Fuzzy logic inference is finished by adopting min-max algorithm; Defuzzification is carried on by applying gravity method. Triangular membership function is selected for Variables e, Ec and $\mathrm{U}$ because it is more flexible than normal 
distribution or Gauss type. Membership function of the parameters e, Ec and $\mathrm{U}$ are shown in figure 4.

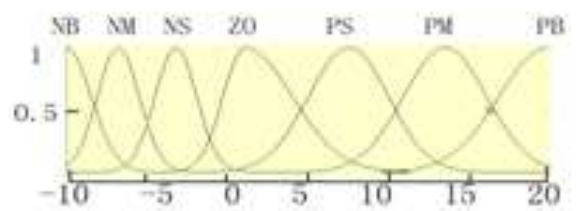

Membership function of $\mathrm{E}$

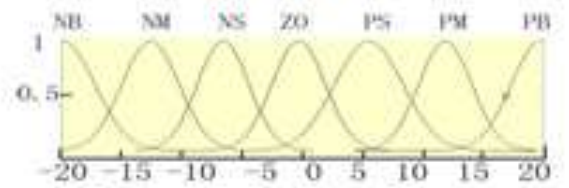

Membership function of $\mathrm{Ec}+$

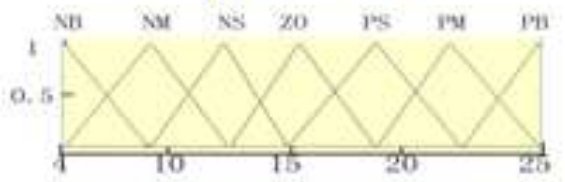

Membership function of $\mathrm{U}$

FIGURE 4. MEMBERSHIP FUNCTION OF E, EC AND U.
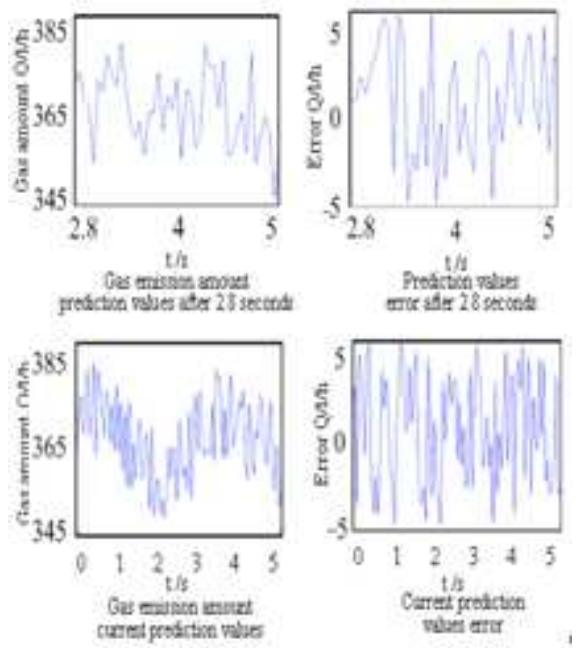

FIGURE 5. NEURAL NETWORK PREDICTION VALUES FOR GAS EMISSION AMOUNT AND ERROR.

\section{NEURAL NETWORK PREDICTION EFFECT OF GAS EMMISSION AMOUNT OF THE OPEN HEARTH FURNACE MOUTH}

Gas emission amount of the open hearth furnace mouth is system actual input variable, it is a key step for the control system to estimate the gas emission current value and predict the gas emission value after 2.8 seconds at the open hearth furnace mouth. Therefore, it is very necessary for neural network to test the prediction effect of gas emission amount at the open hearth furnace mouth. Test method is compared with the actual measured data and neural network prediction data. Figure 5 shows prediction values curve of gas emission amount and the error values curve between the actual measured values and neural network prediction values.

Current prediction values error and prediction values error after 2.8 seconds for gas emission amount at the open hearth furnace mouth are all between -5 and $51 / \mathrm{h}$, as is shown obviously in Figure 5. Results show that neural network prediction effect is quite ideal.

\section{THE PRACTICAL APPLICATION EFFECT}

Control method of gas recovery system adopt neural network and fuzzy control, neural network prediction and fuzzy operation are achieved by s7-300 controller. Control effect shows that gas recovery reach $97.5 \mathrm{~m} 3 / \mathrm{T}$.

\section{CONCLUSION}

This research analyzed in detail control strategies and problems of the gas recovery system at present, put forward a new control model of the gas recovery system based on neural network and fuzzy control, and optimized recycle-using system of steel plant's converter gas by applying this method. The simulation results showed that Current prediction values error and prediction values error after 2.8 seconds for gas emission amount at the open hearth furnace mouth are all between -5 and $51 / h$, and the practice proved the average recovery of gas reached $97.5 \mathrm{~m} 3 / \mathrm{T}$ after applying neural-network adaptive predictive control in practical application.

\section{ACKNOWLEDGMENT}

This work was financially supported by the technology office of Henan Province (102102210421).

\section{REFERENCES}

[1] Haraoka, Takashi; Mogi, Yasuhiro; Saima, Hitoshi. PSA System for the Recovery of Carbon Dioxide from Blast Furnace Gas in Steel Works The Influence of Operation Conditions on $\mathrm{CO} 2$ Separation, KAGAKU KOGAKU RONBUNSHU, 39(5), pp.439-444, 2103.

[2] Fernandes, Jorge Pinto; Dias Lopes, Eduardo Manuel; Maneta, Vicente. New Steel Alloys for the Design of Heat Recovery Steam Generator Components of Combined Cycle Gas Plants, JOURNAL OF ENGINEERING FOR GAS TURBINES AND POWER-TRANSACTIONS OF THE ASME , 132(5), pp.8-12, 2010.

[3] ZY, Tao; CD, Zou. The practicing and study on the recovery and utilization of the coal gas in the Beitai steel corporation, Resources and Energy, Vol F-A, pp. 557-562, 2004.

[4] Huihu, Liu; Shuxun, Sang. Evaluation of the synergetic gas-enrichment and higher-permeability regions for coalbed methane recovery with a fuzzy model, ENERGY, 39(1), pp. 426-439, 2012.

[5] Qi,Zhang; Yan-liang, Gu; Wei, Ti. Supply and Demand Forecasting of Blast Furnace Gas Based on Artificial Neural Network in Iron and Steel Works, Advanced Materials Research, 443(1), pp. 183-188, 2012.

[6] Chun-Yang, Sheng; Jun, Zhao; Wei, Wang; Liu, Ying. A fuzzy modeling method based on T-S model for blast furnace gas system, Shanghai Jiaotong Daxue Xuebao, 46(12), pp. 1907-1913, 2012.

[7] Usón, Sergio; Uche, Javier; Arribas, Juan José; Llera, Rocío; Valero, Alicia. Engineering application of energy analysis: Gas recovery system in steel industry, Proceedings of the 23rd International Conference on Efficiency, Cost, Optimization, Simulation, and Environmental Impact of Energy Systems, 4(1), 2010, pp. 439-446. 
[8] Jia-Yan, Zhang; Zhong-Hai, Ma; Xiao-Bin, Qian; Shao-Ming, $\mathrm{Li}$; Jia-Hong, Lang. Application of optimal control strategy to converter gas recovery system, Zidonghua Xuebao, 38(6), pp. 1017-1024, 2012.

[9] Datta, Amlan; Hareesh, Mavoori; Kumar Kalra, Prem; Deo, Brahma; Boom, Rob. Adaptive neural net (ANN) models for desulphurization of hot metal and steel, Steel Research, 65(11), pp. 466-471, 1994.

[10] Hong-Jun, Wang; De-Xiong, Li; Hui-Juan, Qi; Li-Na, Liu. Application of improved fuzzy PID control algorithm in heating furnace, Advanced Materials Research, 383(1), pp. 760-763, 2012. 